\title{
Formation of the BC Ring System of Upenamide via a Staudinger/ aza-Wittig Reaction
}

\author{
Zhushou Luo, Katherine Peplowski, and Gary A. Sulikowski \\ Department of Chemistry, Vanderbilt University, Nashville, Tennessee 37235
}

\section{Abstract}

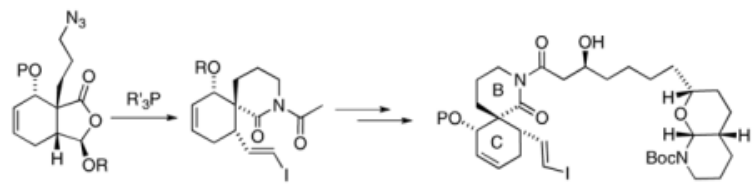

The $\mathrm{BC}$ ring system of upenamide was assembled using a stereoselective Diels-Alder reaction followed by a Staudinger/aza-Wittig/imine hydrolysis reaction. Stereoselective aldol coupling with an aldehyde that incorporates the DE ring system led to an advanced synthetic intermediate en route to the marine alkaloid upenamide.

Upenamide, a unique macrocylic alkaloid was isolated from the crude extract of the marine sponge Echinochalina collected from Derawan Island in Indonesia, as reported by Scheuer in $2000 .{ }^{1}$ Structurally, upenamide features an unsaturated 20-membered macrocycle interconnecting spirooxaquinolizidinone and hemiaminal ring systems; likely derived from a reduced bis-3-alkylpyridine macrocycle according to the biogenesis of related marine alkaloids such as the xestospongins, manzamines and saraines. ${ }^{2}$ The structure of (-)-upenamide was elucidated primarily by a series of NMR experiments. While the absolute configuration of the spirooxaquinolizidinone substructure was assigned by NMR analysis of the $S$ - and $R$-Mosher esters derived at the $\mathrm{C} 11$ hydroxyl group, ${ }^{3}$ the absolute stereochemistry of the bicyclic hemiaminal ring system was left unassigned. Thus, the structural information currently available is in agreement with the $27 \mathrm{R}, 30 \mathrm{~S}, 32 \mathrm{~S}$ or $27 \mathrm{~S}, 30 \mathrm{R}, 32 \mathrm{R}$ isomers (Figure 1). One approach to distinguishing between these two structures is by enantioselective total synthesis of upenamide and correlation with natural (-)-upenamide.

In bioassays, upenamide did not show cell growth inhibition against P388, A549 and HT29 cancer cell lines. Further biological evaluation has not been reported perhaps due to insufficient quantities of upenamide. Since sponge collection from the Derawan island is now strongly restricted it is doubtful the current supply of upenamide will be increased by isolation, leaving total synthesis as the only viable material supplement. ${ }^{4}$

As a means of full stereochemical assignment of (-)-upenamide, our synthetic strategy required delivery of 27R, 30S, 32S upenamide and the mirror image of the corresponding 27S, 30R, $32 \mathrm{R}$ isomer (Figure 1) by stereoselective aldol coupling of racemic ( \pm )-2 and (-)-3 followed by the eventual completion of the upenamide ring system (Scheme 1). This synthetic assembly, in principle, provides sufficient stereochemical information to unambiguously assign the structure of (-)-upenamide by spectral and optical properties comparison to natural material. Earlier we described a stereocontrolled synthesis of $(-)-3 .{ }^{4 \mathrm{c}}$ Herein we describe a 
racemic synthesis of the $\mathrm{BC}$ spirocyclic imide $( \pm)-2$ and stereoselective aldol reaction with aldehyde (-)-3 to deliver the advanced synthetic intermediate $\mathbf{1}$ and its isomer (not shown).

The preparation of the spirocyclic ring system $( \pm)-2$ presents a significant synthetic challenge due to the required control of three contiguous stereocenters including a central quaternary carbon. ${ }^{5}$ A logical precursor to $( \pm)-2$ is aldehyde $\mathbf{4}$ which we anticipated could be produced by a reductive cylization of azido lactone $\mathbf{5}$, a bicyclic ring system derived from a Diels-Alder reaction (Scheme 1). Feringa has investigated the Diels-Alder reaction of gammaalkoxybutenolides, however, only an intramolecular example has examined the effect of an alpha-alkyl group on the reactivity and stereoselectivity of this class of dienophiles. ${ }^{6}$ Under thermal conditions no reaction was observed between 1-tert-butyldimethylsiloxybutadiene and butenolide 6 (Scheme 2). ${ }^{7}$ In contrast, the unsubstituted gamma-methoxybutenolide 7 readily underwent a Diels-Alder reaction with the same diene to give cycloadduct 9, albeit with 4:1 endo/exo selectivity. By way of contrast, when 2- bromobutenolide $\mathbf{8}$ was heated at reflux in toluene with 1-tert-butyldimethylsiloxybutadiene, the endo adduct $\mathbf{1 0}$ was isolated exclusively as a white crystalline solid. ${ }^{8}$ Subsequently, the bromo group located at the ring fusion allowed introduction of a three-carbon fragment by way of a Keck allylation. Unfortunately the selectivity of the radical-mediated allylation was modest, affording a chromatographically separable mixture of cis (11) and trans (12) fused isomers resulting in $63 \%$ and $30 \%$ yield, respectively. The cis isomer (11) was then subjected to a hydroboration-oxidation sequence to afford alcohol 13 in $80 \%$ yield. Substitution of the hydroxyl group with an azido group was accomplished using diphenylphosphoryl azide and base (DBU) 9 to set the stage for the key Staudinger-aza-Wittig reaction. ${ }^{10}$ To this end, azide 14 was heated in toluene at reflux with a slight excess of triphenylphosphine. Following consumption of $\mathbf{1 4}$, as determined by TLC analysis, the reaction was quenched with water. Under these conditions the major product proved to be aldehyde 15, the epimer of the desired aldehyde (4) as determined by singlecrystal X-ray analysis. Examination of a representation of the X-ray structure (15) shows epimerization relieved an unfavorable 1,3-diaxial interaction with the TBS ether group.

We reasoned that, in contrast to an aldehyde, a carboxylic acid would be far less prone to epimerization. For this reason we examined the reductive cyclization of anhydride $\mathbf{1 7}$ (Scheme 3 ), derived from methyl acetal 14 in two steps. A solution of anhydride $\mathbf{1 7}$ was stirred at room temperature with a slight excess of trimethylphosphine to afford carboxylic acid $\mathbf{1 8}$ as a single isomer. Reduction of $\mathbf{1 8}$ with $\mathrm{LiAlH}_{4}$ followed by oxidation with Dess-Martin periodinane gave aldehyde 20 without any epimeric product (15) observed. Takai olefination $\left(\mathrm{CrCl}_{2}\right.$, $\mathrm{CHI}_{3}$ ) of $\mathbf{2 0}$ gave vinyl iodide $\mathbf{2 1}$ and after $\mathrm{N}$-acetylation spirocyclic imide $\mathbf{2}$ was obtained.

While this route delivered the BC spirocyclic ring system (2) it was somewhat cumbersome, as it required manipulation of the oxidation state of the carboxaldehyde group. We reasoned that epimerzation of aldehyde $\mathbf{2 0}$ to $\mathbf{1 5}$ was promoted by methoxide ion produced in the course of the Staudinger/aza-Wittig/imine hydrolysis sequence. In order to avoid production of this moderately strong base we chose to examine the cyclization of acetate $\mathbf{2 2}^{\mathbf{1 1}}$ (Scheme 4 ). After screening various reaction conditions, we determined conversion of $\mathbf{2 2}$ to aldehyde $\mathbf{2 0}$ via imine $\mathbf{2 2 a ^ { 1 2 }}$ was effected by microwave $\left(20 \mathrm{Watts}, 60^{\circ} \mathrm{C}\right)$ irradiation for 5 minutes. Introduction of water and further irradiation for 10 minutes thereafter provided 20 in $80-85 \%$ yield with minimal epimerization $(\mathbf{2 0 / 1 5}, 10: 1)$.

A key consideration in the proposed aldol coupling of imide ( \pm )-2 and aldehyde ( - -) 3 to provide 1 was the stereoselectivity of the aldol reaction (vis-à-vis control of the $\mathrm{C} 2$ configuration) relative to the chirality harbored within the enolate derived from imide $( \pm)-2$. In this way, a stereoselective aldol in the correct sense would fashion four of the five stereocenters of the complex spirooxaquinolizidinone ring system of upenamide. After examining various metal enolates (including lithium and boron) it was determined that the titanium enolate derived from 
( \pm )-2 condensed with n-butyraldehyde to provide one major aldol isomer ( $\mathrm{dr} 20: 1)$ in $75 \%$ yield. The reaction, which utilized an excess of titanium(IV), was proposed to proceed by way of chelate transition state $\mathbf{2 3}$ whereby the aldehyde approaches the titanium enolate from the diastereotopic face opposite the sterically cumbersome TBS group. ${ }^{13}$ The configuration of the C2 secondary alcohol of $\mathbf{2 4}$ has been tentatively assigned based on the transition state model 23.

Under identical reaction conditions 3.7 equivalents of imide ( \pm )-2 underwent an aldol reaction with aldehyde (-)-3 to give two inseparable isomers (Scheme 6) in $95 \%$ yield. No other isomers were observed within detection limits of ${ }^{1} \mathrm{H}$ and ${ }^{13} \mathrm{C}$ NMR.

In summary, we have developed a stereocontrolled assembly of the complex spirocyclic ring system embedded in the marine alkaloid upenamide. In addition we have developed reaction conditions that serve to merge spirocyclic imide ( \pm )-2 with aldehyde (-)-3 and in the process we have controlled the $\mathrm{C} 2$ configuration of upenamide. Remaining synthetic challenges to be addressed in advancing $\mathbf{1}$ to upenamide are construction of the macrocylic ring system and completion of the spirooxaquinolizidinone ring system.

\section{Supplementary Material}

Refer to Web version on PubMed Central for supplementary material.

\section{Acknowledgements}

We thank the National Institutes of Health (GM067726-05) for their support of this research. We also thank Joseph Reibenspies (Center for Chemical Characterization and Analysis, Texas A\&M University) for determining the X-ray crystal structure of $\mathbf{1 5 .}$

\section{References}

1. Jimenez JI, Goetz G, Mau CMS, Yoshida WY, Scheuer PJ, Williamson RT, Kelly M. J Org Chem 2000;65:8465-8469. [PubMed: 11112565]

2. (a) Baldwin JE, Whitehead RC. Tetrahedron Lett 1992;33:2059-2062. (b) Tsuda M, Kobayashi J. Heterocycles 1997;46:765-794. (c) Guo YW, Madaio A, Trivellone E, Scognamiglio G, Cimino G. Tetrahedron 1996;52:8341-8348. (d) Cutignano A, Tramice A, De Caro S, Villani G, Cimino G, Fontana A. Angew Chem Int Ed Engl 2003;42:2633-2636. [PubMed: 12813739]

3. (a) Dale JA, Mosher HS. J Am Chem Soc 1973;95:512-519. (b) Trost BM, Belletire JL, Godleski S, McDougal PG, Balkovec JM, Baldwin JJ, Christy ME, Ponticello GS, Varga SL, Springer JP. J Org Chem 1986;51:2370-2374.

4. For earlier synthetic work on upenamide, see: (a) Reid M, Taylor RJK. Tetrahedron Lett 2004;45:41814183. (b) Maia AA, Mons S, Gil RPD, Marazano C. Eur J Org Chem 2004:1057-1062. (c) Kiewel K, Luo ZS, Sulikowski GA. Org Lett 2005;7:5163-5165. [PubMed: 16268528] (d) Ménard-Moyon C, Taylor RJK. Eur J Org Chem 2007:3698-3704. (e) Schmidt JP, Beltrán-Rodil S, Cox RJ, McAllister GD, Reid M, Taylor RJK. Org Lett 2007;9:4041-4044. [PubMed: 17764195]

5. (a) Corey EJ, Guzman-Perez A. Angew Chem Int Ed Engl 1998;37:388-401. (b) Denissova I, Barriault L. Tetrahedron 2003;59:10105-10146.

6. (a) Feringa BL, Dejong JC. J Org Chem 1988;53:1125-1127. (b) Jauch J. Angew Chem Int Ed Engl 2000;39:2764-2765. [PubMed: 10934420]

7. Kamatani A, Overman LE. J Org Chem 1999;64:8743-8744.

8. Maestro MC, Barquilla MC, Martin MR. Tetrahedron-Asymm 1999;10:3593-3599.

9. Thompson AS, Humphrey GR, Demarco AM, Mathre DJ, Grabowski EJJ. J Org Chem 1993;58:58865888. 
10. (a) Jiang B, Yang CG, Wang J. J Org Chem 2002;67:1396-1398. [PubMed: 11846695] (b) Neubert BJ, Snider BB. Org Lett 2003;5:765-768. [PubMed: 12605510] (c) Wang J, Sakamoto S, Kamada K, Nitta A, Noda T, Oguri H, Hirama M. Synlett 2003:891-893.

11. Acetate 22 was prepared from methyl acetal 14 in two-steps (i. $1 \mathrm{M} \mathrm{KOH}, 18$-crown-6, dioxane, 50 ${ }^{\circ} \mathrm{C}$; ii. $\mathrm{Ac}_{2} \mathrm{O}$, DMAP, pyridine, $\mathrm{CH}_{2} \mathrm{Cl}_{2}$ ).

12. Compound 22a has only been isolated and characterized by ${ }^{1} \mathrm{H}$ NMR only. Subsequent hydrolysis led to aldehyde 20 .

13. Nerz-Stomes M, Thornton ER. J Org Chem 1991;56:2489-2498.

Org Lett. Author manuscript; available in PMC 2008 November 22. 


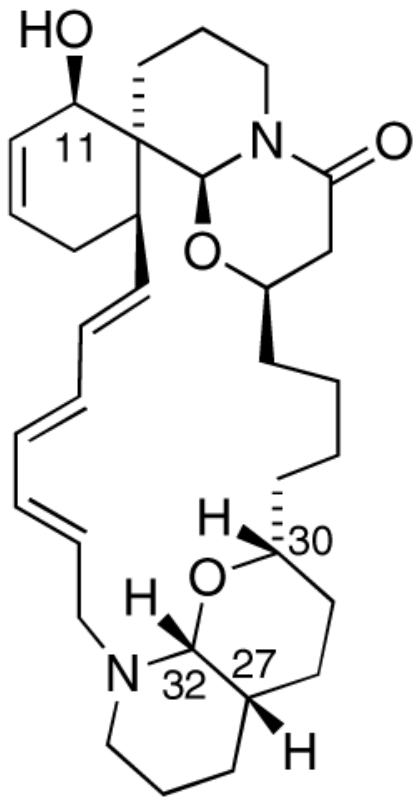

$27 R, 30 S, 32 S$

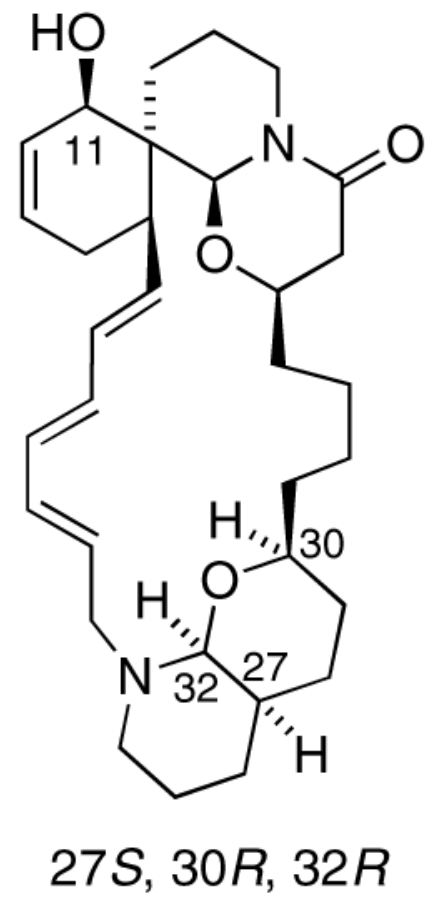

Figure 1.

Possible upenamide structures.

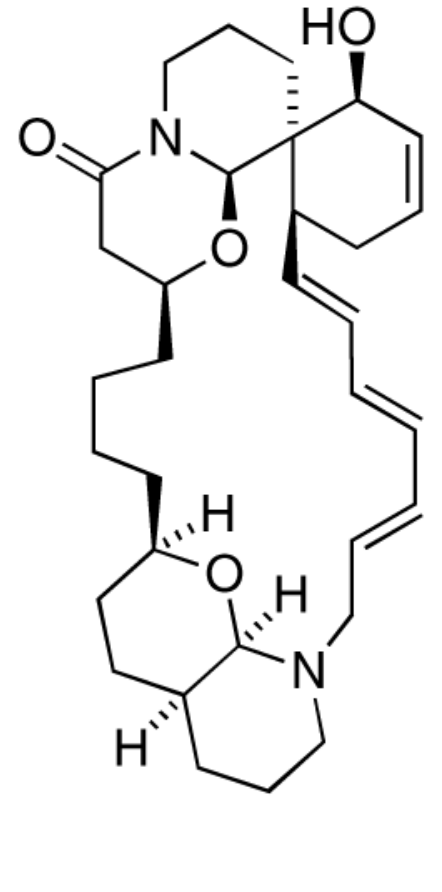



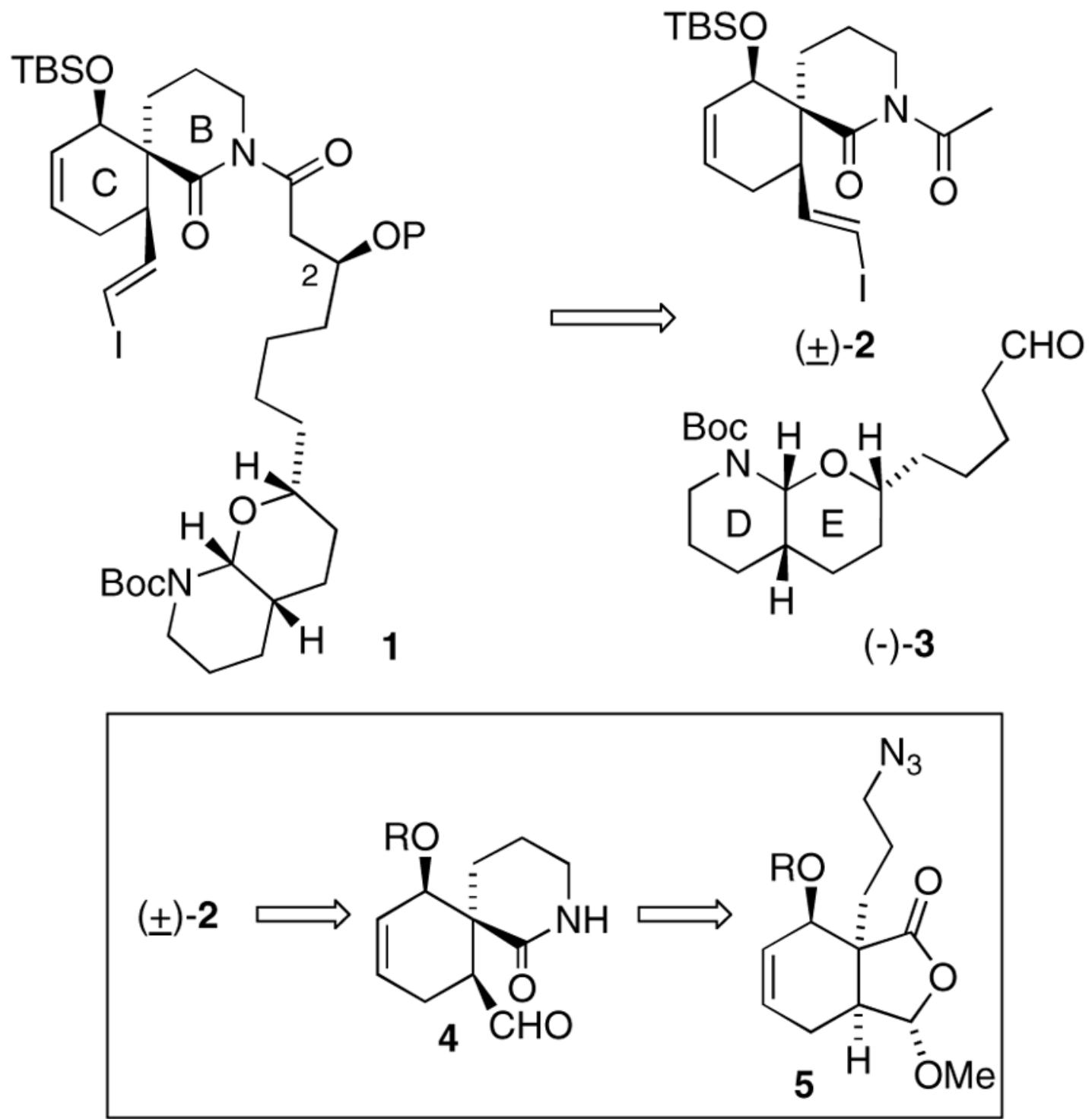

Scheme 1. 


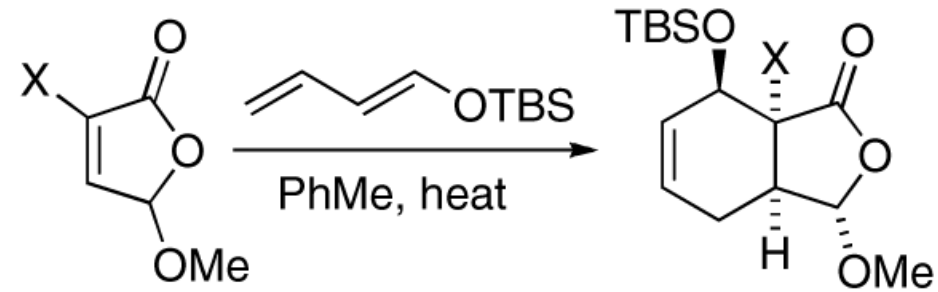
$6 \mathrm{X}=\left(\mathrm{CH}_{2}\right)_{3} \mathrm{NHBoc}$
$7 \mathrm{X}=\mathrm{H}$
$9 \mathrm{X}=\mathrm{H}(65 \%)$
$8 \mathrm{X}=\mathrm{Br}$
$10 X=B r(72 \%)$

TBSO<smiles>C=CC[SnH2]CC(C)(C)C</smiles>

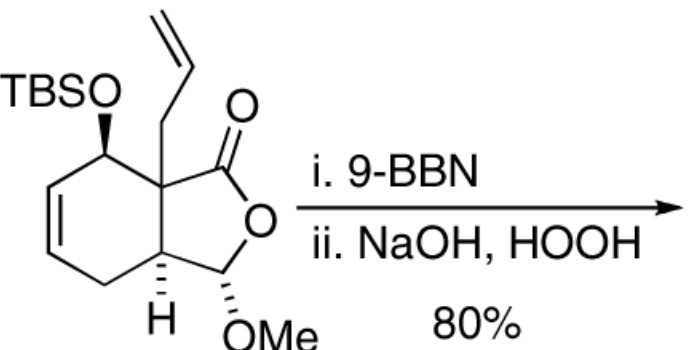

10

$11 \alpha$-allyl (63\%)

$12 \beta$-allyl (30\%)

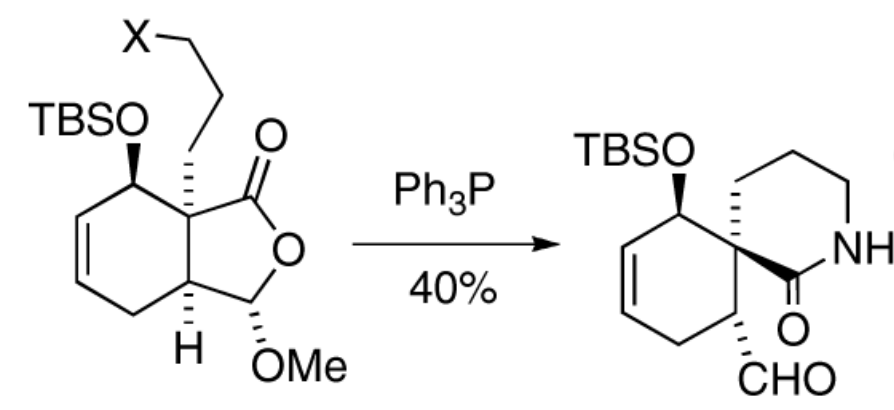

$(\mathrm{PhO})_{2} \mathrm{P}(\mathrm{O}) \mathrm{N}_{3}-13 \mathrm{X}=\mathrm{OH}$ DBU, $85 \% \longrightarrow 14 \mathrm{X}=\mathrm{N}_{3}$

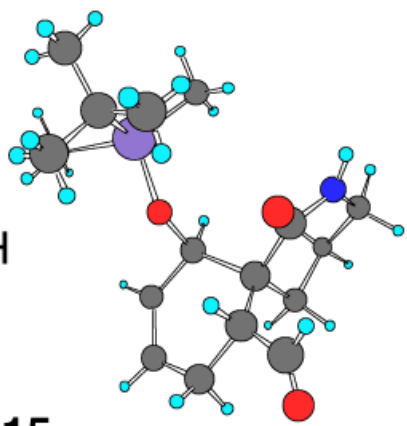

15

Scheme 2. 


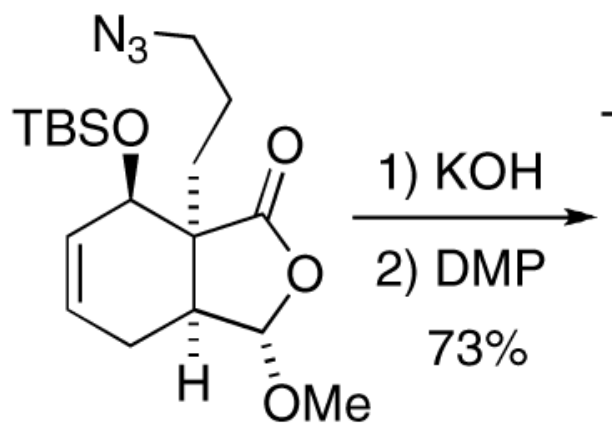

14

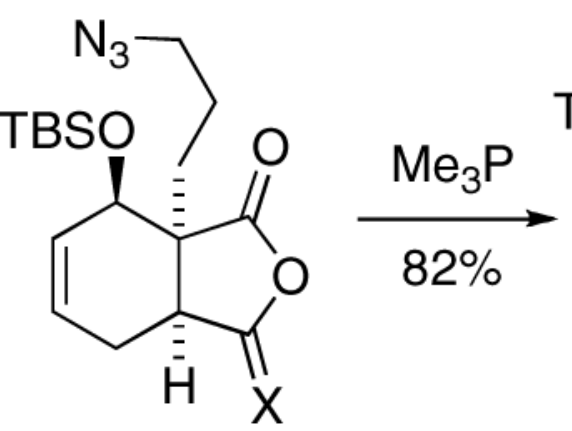

$16 \mathrm{X}=\mathrm{H}, \mathrm{OH}$

$17 X=0$

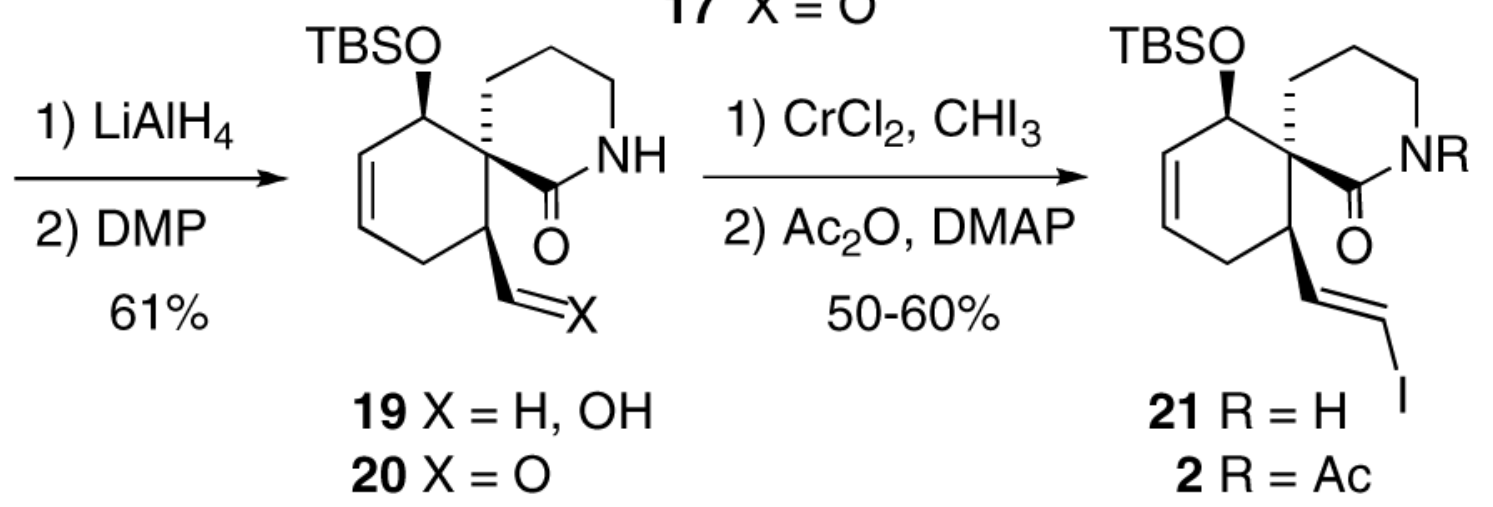

Scheme 3. 
<smiles>CC(C)O[C@@H]1OC(=O)[C@@]2(CCC[NH3+])[C@@H]1CC=C[C@H]2OS(C)(=O)=O</smiles>

22

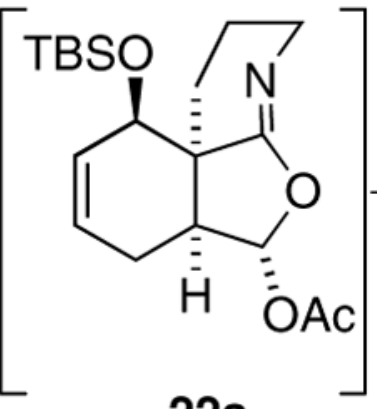

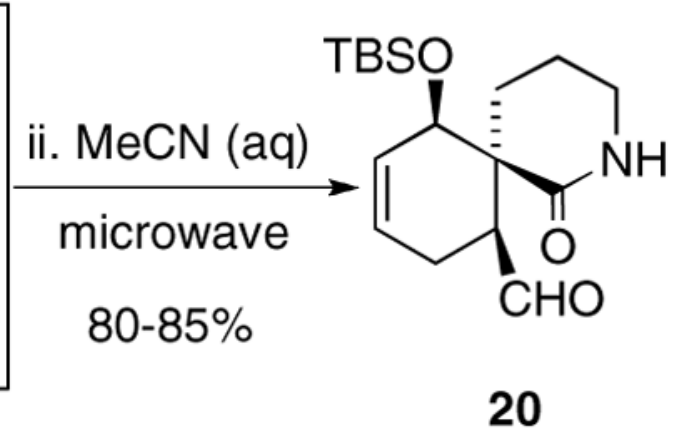

Scheme 4. 


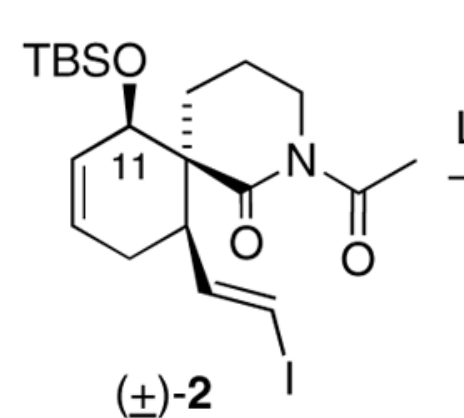

$( \pm)-2$
LHMDS, CITi(Oi-Pr) 3

$\mathrm{Et}_{2} \mathrm{O},-78{ }^{\circ} \mathrm{C}$ then $\mathrm{n}-\mathrm{C}_{3} \mathrm{H}_{7} \mathrm{CHO}$

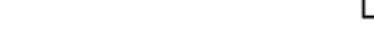

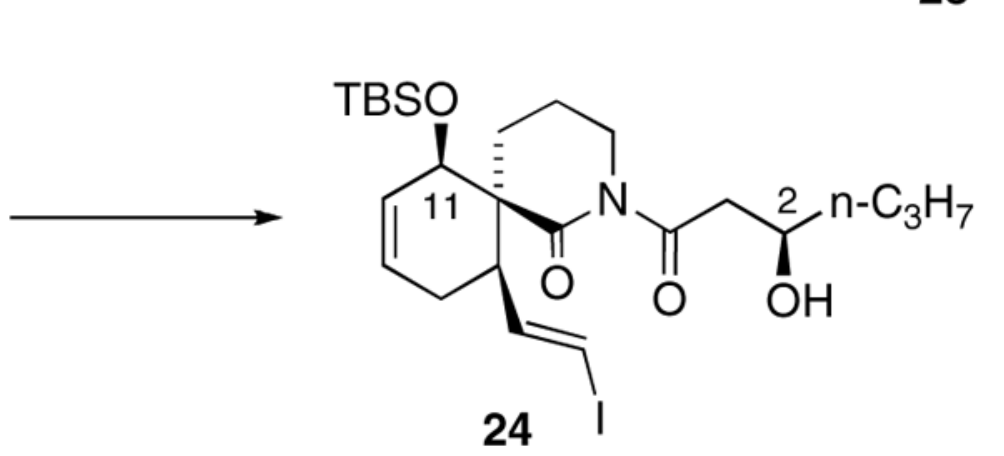

Scheme 5. 


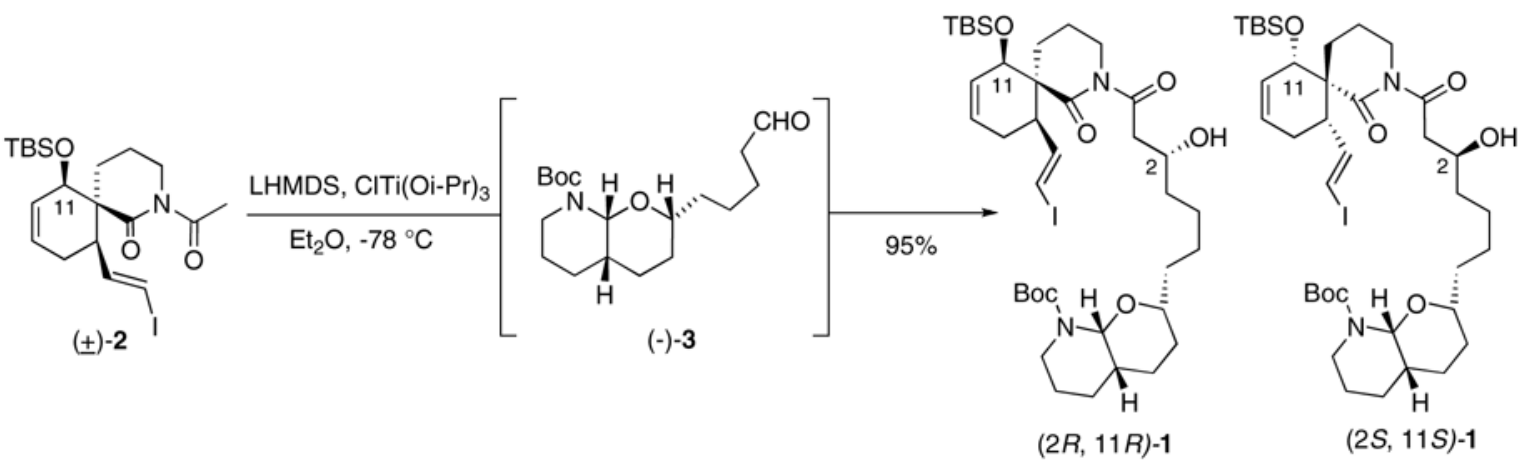

Scheme 6. 